\title{
THE COMPLEX POINT CLOUD FOR THE KNOWLEDGE OF THE ARCHITECTURAL HERITAGE. SOME EXPERIENCES.
}

\author{
C. Aveta ${ }^{\text {a }}$, M. Salvatori ${ }^{\text {b }}$, G. P. Vitelli ${ }^{\mathrm{c}}$ \\ a $\mathrm{PhD}$ in History and Conservation of Architectural Heritage at the University of Naples Federico II - claveta@unina.it \\ ${ }^{\mathrm{b}} \mathrm{PhD}$ in History and Conservation of Architectural Heritage at the University of Naples Federico II - maridasalvatori@ virgilio.it \\ ${ }^{c} \mathrm{PhD}$ in History and Conservation of Architectural Heritage at the University of Naples Federico II - gianpaolovitelli@ gmail.com
}

KEY WORDS: Laser Scanner,

\begin{abstract}
:
The present paper aims to present a series of experiences and experimentations that a group of $\mathrm{PhD}$ from the University of Naples Federico II conducted over the past decade. This work has concerned the survey and the graphic restitution of monuments and works of art, finalized to their conservation. The targeted query of complex point cloud acquired by $3 \mathrm{D}$ scanners, integrated with photo sensors and thermal imaging, has allowed to explore new possibilities of investigation.

In particular, we will present the scientific results of the experiments carried out on some important historical artifacts with distinct morphological and typological characteristics.

According to aims and needs that emerged during the connotative process, with the support of archival and iconographic historical research, the laser scanner technology has been used in many different ways. New forms of representation, obtained directly from the point cloud, have been tested for the elaboration of thematic studies for documenting the pathologies and the decay of materials, for correlating visible aspects with invisible aspects of the artifact.
\end{abstract}

\section{INTRODUCTION ${ }^{\mathrm{c}}$}

The great diffusion of Geomatics and the development of threedimensional scanning technologies, have given to the restorers new powerful tools for the documentation and the knowledge of the historical heritage.

This new approach for surveying, has required a profound reflection on the impact that these innovations bring within the scientific discipline of restoration and has encouraged the restorers to start several experiments in order to explore the new possibilities and the new problems.

Two are the innovative aspects that are more interesting for the field of Conservation. First, the automation of the metric measurement process that allows to distinguish between the interpretative model of the surveyor and the set of measured data by the instrument (the 3D point cloud). In this way, the subjective interpretation, which remains essential for the cognitive process, is moved in a step subsequent to that of the measurement on site.

For this reason, the 3D point cloud, not modified by manipulations or filtering, can be considered a noninterpretative document of a state of fact temporally defined that preserves part of the authentic dimension of the reality from which it derives. As a document, the $3 \mathrm{D}$ point cloud can be queried with information technology tools to get often significant and unexpected results.

The second interesting aspect is that the $3 \mathrm{D}$ point cloud can be integrated with other data from different sensors. This allows to capture both metric data that further data concerning some physical characteristics of the surface in a single automatic measurement.

The multidimensionality of information returned from the entire system (the complex point cloud) allows to create new types of analysis and representations useful for the understanding of visible and invisible aspects of the cultural heritage.

The present paper aims to present a series of experiences and experimentations that a group of $\mathrm{PhD}$ from the University of
Naples Federico II conducted over the past decade ${ }^{1}$. This work has concerned the survey and the graphic restitution of monuments and works of art, finalized to their conservation. The targeted query of complex point cloud acquired by 3D scanners, integrated with photo sensors and thermal imaging, has allowed to explore new possibilities of investigation. In particular, we will present the scientific results of the experiments carried out on some important historical artifacts with distinct morphological and typological characteristics.

According to aims and needs that emerged during the connotative process, with the support of archival and iconographic historical research, the laser scanner technology has been used in many different ways. New forms of representation, obtained directly from the point cloud, have been tested for the elaboration of thematic studies for documenting the pathologies and the decay of materials, for correlating visible aspects with invisible aspects of the artifact.

\section{THE DOCUMENTATION OF THE STATE OF FACTS, NEW FORMS OF REPRESENTATION ${ }^{\text {a }}$}

\subsection{The multidimensionality of information of the complex point cloud}

One of the most innovative aspects, introduced by the laser scanner technology, consist of the multidimensionality information acquired by the instrument.

By only one automatic acquisition of data, the remote sensing system can provide, at the same time, both metrical than qualitative and punctual information, referred to specific

\footnotetext{
1 These aspects have been studied during the three-year period 20092011, under the PhD in History and Conservation of Architectural Heritage at the University of Naples Federico II, and have been the subject of a research thesis entitled: Potential and Perspectives of Advanced detection technologies for the preservation of historic architecture (author: G. P. Vitelli, tutor A. Aveta and Cotutor B. G. Marino). This research has followed a line of study and experimentation that is still ongoing.
} 
features of the exterminated artifacts, such as the surfaces reflectance or the color.

Integrating a photo sensor, for example, it is possible to associate, automatically, the three RGB values for the univocal and punctual determination of the color of a surface. It is virtually possible, in the same way, to integrate in the system a sensor for thermographic surveys or one for hyper spectral imaging, and so on.

A point cloud like that it is called complex and it appears, from a formal point of view, like an organized and finite set of $n$ dimensional vectors, in which $\mathrm{n}$-scalars contain both metrical information (the three cartesian or polar coordinates of the point) and other scalar values. These, automatically associated with metric information, make it possible not only to process a precise three-dimensional metric detection, but also multidimensional analysis of the reality extraordinarily complex and innovative.

Below will be illustrated some experiences where the need of solving specific problems in the documentation of state of facts, for the purpose of the restoration project, has allowed to experience both aspects from the specific point of view of the preservation of cultural heritage.

\subsection{The church of S. Maria di Piedigrotta in Pizzo Calabro.}

The first case is that of the survey of the church of S. Maria di Piedigrotta in Pizzo Calabro, a sacred architectural space in large part excavated inside a natural sandstone ridge that stands a few meters from the beach of the riviera Prangi. It is a very suggestive site formed by several interconnected caves, with remarkable height differences and a leaning planking level towards the beach that ensures the outflow of muddy and meteoric waters that seep from the ridge and converge within the church in special tanks placed at the sides of the altar.

The uniqueness of constructive typology, morphological characters, complex three-dimensional compartmentalization of spaces, non-euclidean geometry composed of organic, curved and irregular shapes excavated in the rock, the crowd of masonry statues depicting scenes and religious figures that encumber not only the walls, but also the free space, made very problematic the traditional metrical survey. For this reason, the Superintendence for Architectural Heritage in 2008 demanded a laser scanner survey for the realization of a 3D model that would effectively represent the complexity of the space and to obtain the plan, the sections, and the traditional prospect of the church with an adequate precision.

The survey was completed with approximately 52 scan positions that could cover both the interior and exterior of the church and it was georeferenced through an accurate preliminary topographic survey carried out by a total station theodolite.

The resulting point cloud was then segmented into four parts and transformed into a polygonal mesh surface which, appropriately sectioned by secant planes, allowed to generate, in addition to an accurate 3D model, numerous maps and sections capable of showing the space complexity of the church also through two-dimensional representations. (Figure 1)

From this experience, immediately became clear the effectiveness of the laser scanner technology in all cases where the geometric complexity of an artifact requires a large number of sampling points needed to fully describe the geometry, regardless of the physical dimension.

However, the "complexity" factor is a relative factor that also depends on the purpose of the representation and not just by the geometry or physical size of the objects.

If the purpose of the representation is to investigate the real form and not the ideal generating geometry, not presupposing a priori the planarity of the surfaces, the orthogonality and the linearity of the edges, by investigating in detail the surface grain at a close scale, analyzing deformations over time, deviations from generating geometry, etc., it is clear that it will not be enough to sample the points that describe the ideal geometry but a widespread sampling on all surfaces will be required, regardless of size and of the geometric complexity of the artifact, as even a simple geometry such as a parallelepiped, studied under this light, may prove to be much more complex than it appears.

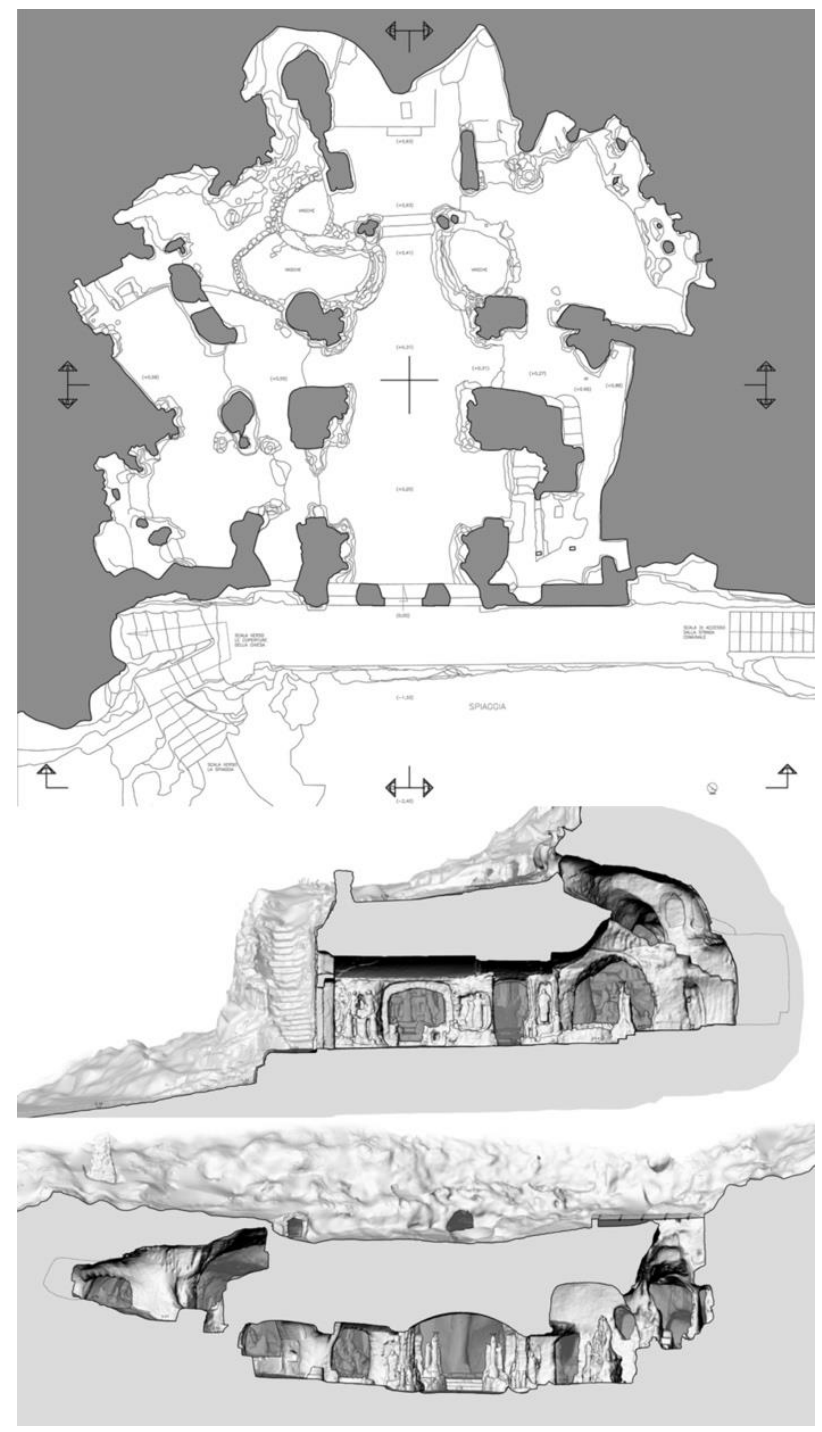

Figure 1. Two-dimensional representations of the model

For the Conservation of architectural and artistic heritage, it is indispensable that the survey is done by operating widespread sampling with as objective as possible criteria, not spoiled by the geometric pre-judgment of the surveyor.

In the interest of the restoration, a large number of samples must be collected regardless of the size and geometric complexity of the artifact to be detected.

\subsection{The Matres Matutae statues of Capua}

Under this light, the survey of small artifacts, such as small statues or movable property, can be a particularly complex operation that may require even more measurements than an architectural survey. 


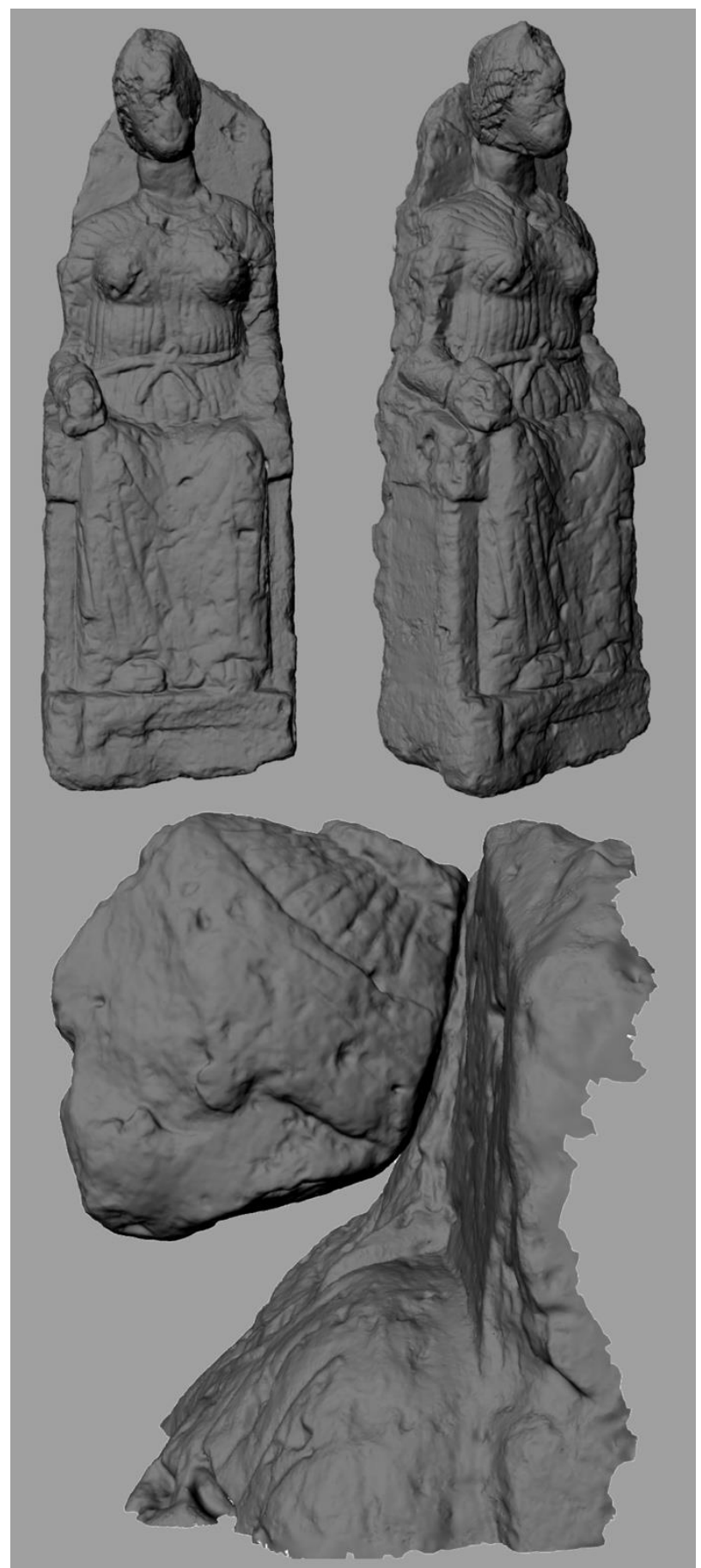

Figure 2. The virtual model of the statue "A" before and after the de-restoration.

We mention the case of the survey, in 2009, of two statues in the Archaeological Museum of Capua in Campania, belonging to the collection of Matres Matutae from the ancient Capua.

The statues are part of a collection of over 160 finds from a period between the $6^{\text {th }}$ and the $1^{\text {st }}$ century BC. Some of these were found by chance at the end of the $19^{\text {th }}$ century, in an agricultural fund near Capua and only later excavated with scientific criteria by the archaeologist A. Maiuri. During the Second World War they were again buried in order to preserve them from the bombing and later unburied at the end of the conflict, suffering various damage such as detaching of some heads from their busts. These were glued, in a awkward restoration, without paying much attention to the original placement.

For this reason, in 2009, as part of a general reopening of the collection to the public, it was decided to conduct a derestoration of the heads and a new placement according to more rigorous scientific criteria. The archaeologist responsible for operations, prof. A. De Simone, therefore requested a high precision laser scanner survey of two of the statues of the collection.

The work consisted of documentation of the current state of the statues, prior to de-restoration and the survey of the heads and busts, including contact surfaces, after their separation.

The ultimate aim was to carry out, along with the archaeologist, virtual repositioning simulations with the help of some original excavation drawings by A. Maiuri before the final intervention.

To accomplish these operations, it was necessary to acquire approximately 180 scans with a Konica Minolta Optical Triangular Scanner and build models with polygonal meshes of high resolution, intentionally colorless, to permit the recognition of matches and connections useful for the correct positioning of the parts. (Figure 2)

\subsection{The testing of a new workflow to get new forms of representation}

The need to explore the innovative possibilities offered by the complex point cloud for the documentation of artifacts of historical-artistic interest, has led to the elimination of most manipulations and approximations necessary for the construction of polygonal mesh surfaces and to explore new forms of representation using the complex point cloud without automatic filterings that can significantly alter the authenticity of the source data.

In this particular workflow, point clouds are acquired at a very high density, specifically calibrated for purpose, aligned with Multi Station Adjustment (MSA) software methods that allow you to achieve standard deviations below scanner resolution and manually cleaned from unnecessary points or instrumental noise.

The point clouds are then carefully segmented to create a single polydate at full resolution and with a density of points as homogeneous as possible for all surfaces, even though automatic filtration is not used. This is possible thanks to a careful design of scanning positions that takes into account both the density of the final polydata and the homogeneity in the acquisition of the reflectance data.

Point clouds, so elaborate and colored with RGB data or with false colors, are then used as they are in real orthoprojection to achieve traditional two-dimensional tables as well as to build three-dimensional models that can generate highly innovative representations and investigations.

\section{5 the survey of a monumental staircase of the Castel Capuano complex in Naples.}

An interesting field test on this approach has been the survey of one of the monumental staircases of the Castel Capuano complex in Naples. ${ }^{2}$

The survey was required in order to understand the intricate interpenetration of some environments resulting from historical stratifications and to analyze some abnormalities such as the different inclination of the ramps and the interruption of the connection between the staircase and the second floor where there is an important environment called "The Cabinet of the

\footnotetext{
which is the subject of an agreement between the Ministry of Justice and the University of Naples Federico II.
} 
Queen Giovanna". The connection had been closed in the second post-war period by the interposition of an armored concrete slab at the end of one of the ramps.

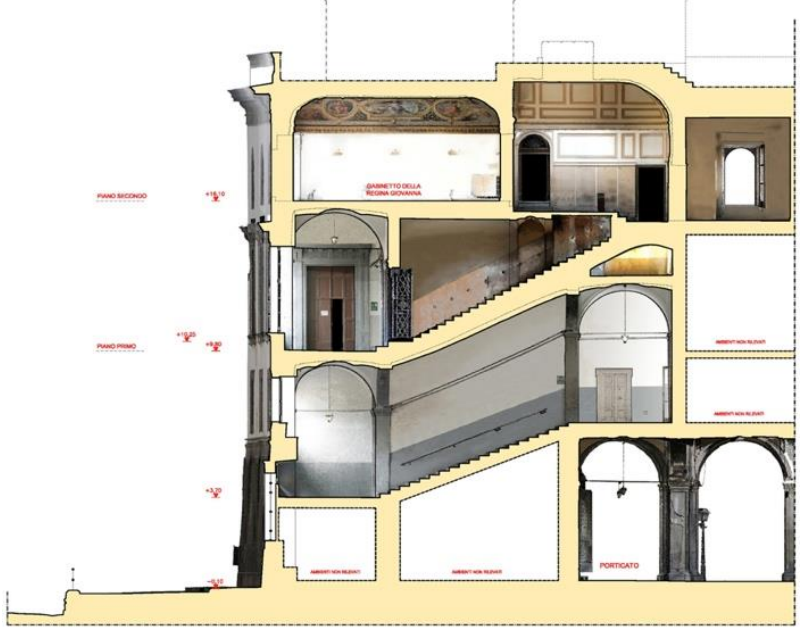

Figure 3. Section of the staircase

This geometric "knowledge" operation was indispensable for verifying a hypothesis of restoring the historical connection after the relocation of the Courtroom to the new business district of Naples.

Thus, a laser scanner survey was carried out for a 3D representation of the staircase and all spaces connected to it.

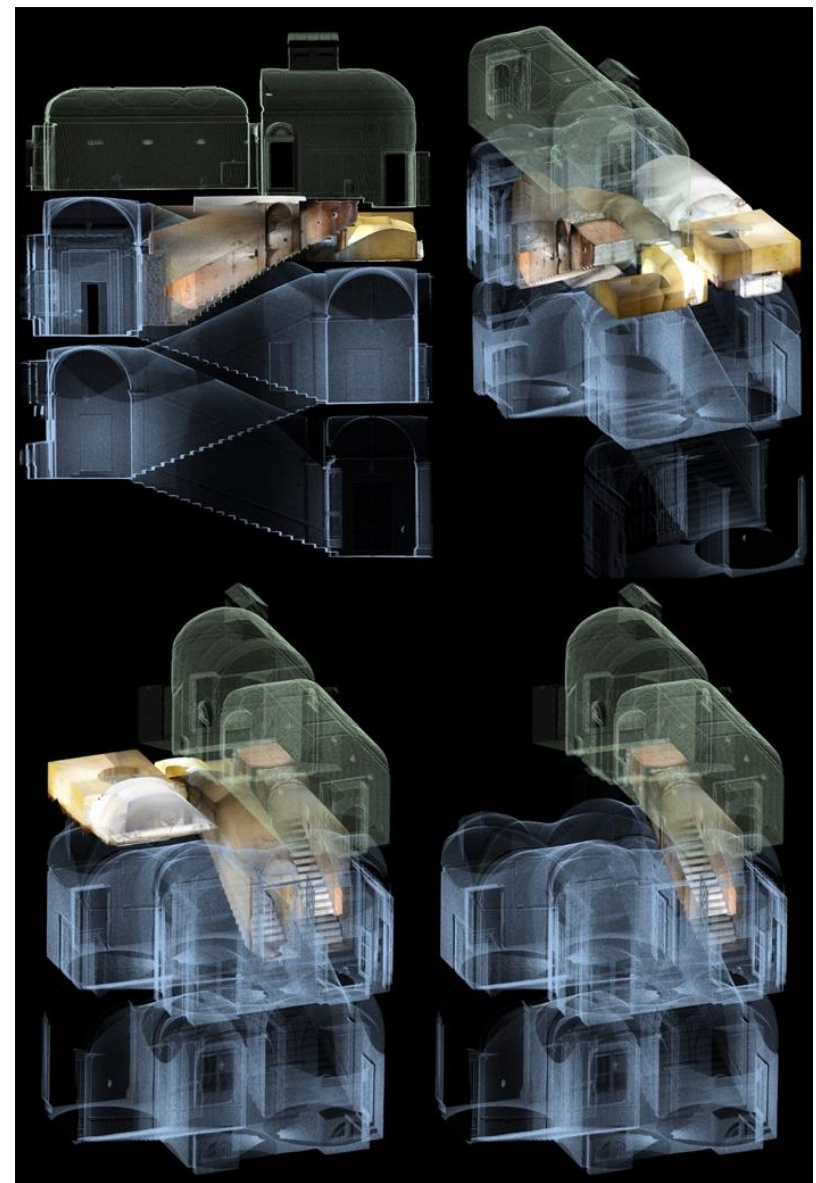

Figure 4. The point cloud treated with different colors and densities to build a special three-dimensional model.
On site, the first difficulty was to georeferencing adjoining environments that are no longer physically connected. This was done by placing targets outside the structure, visible through the windows of various environments, and then refining alignments with an MSA software.

From high resolution captured point clouds, colored with the RGB data of a photographic sensor, were extracted plants, sections and precision statements used for the analysis of the degradation and for the restoration project. (Figure 3)

Finally, the point cloud was treated with different colors and densities to build a three-dimensional model that can visualize, through a play of transparency and opacity, the relationships between architectural spaces as in a sort of color radiography. (Figure 4)

\subsection{The church of Saints Cosma and Damiano in Naples}

A similar experience was also done for the restoration of the church of Saints Cosma and Damiano in Naples.

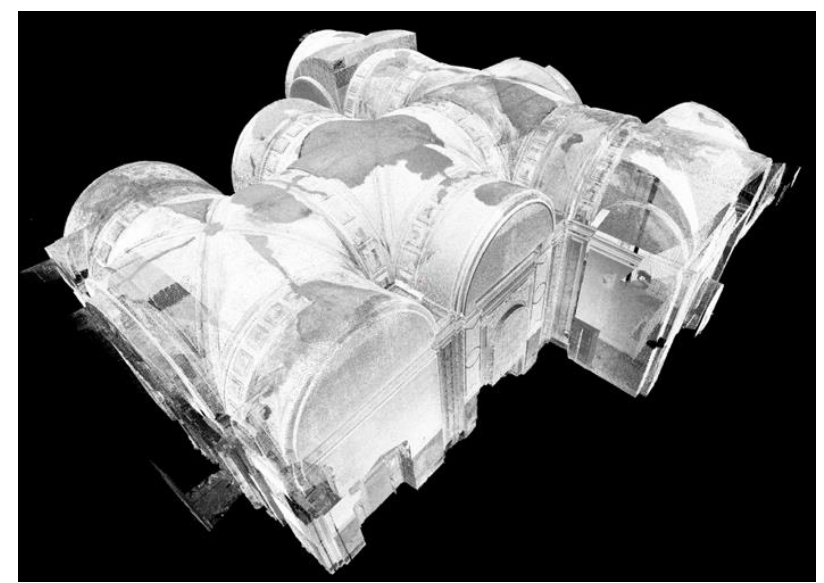

Figure 5. The point cloud of the inner volume of the church.

This building, which was originally known as the Banchi Nuovi Loggia, a square-shaped loggia covered by nine ribbed vaults, located on the ancient route near the edge of the Neapolis ridge has undergone numerous transformations that have altered its configuration over the centuries. Today the building looks like a baroque church with a greek cross plan, where the ancient impost blocks in piperno, still existing, are drowned in the masonry and hidden by the plaster, while the ancient vaults have been reconfigured through the building of fake vaults and high infill walls.

These transformations have made the structure particularly vulnerable to earthquake so that today the church presents a considerably complex of damages, mistakenly interpreted in a post-earthquake intervention in 1980. After a long period of closure and abandonment during that the church was further vandalized and plundered, in 2011 it was decided to restore it. Given the complexity of the its status, a wide diagnostic and laser scanning campaign was needed to properly interpret the structural behavior and make a more targeted and minimally invasive consolidation intervention.

The survey, thus, permitted not only to obtain a threedimensional model of the church (Figure 4), useful for any kind of evaluation - particularly with regard to geometry and genesis of the vaults, indispensable support for historical investigation but also to create classical representations: maps, prospects, and sections, with geometric precision to allow assessments both on the lesion-structural framework and on surface degradation, directly interrogating the model. 


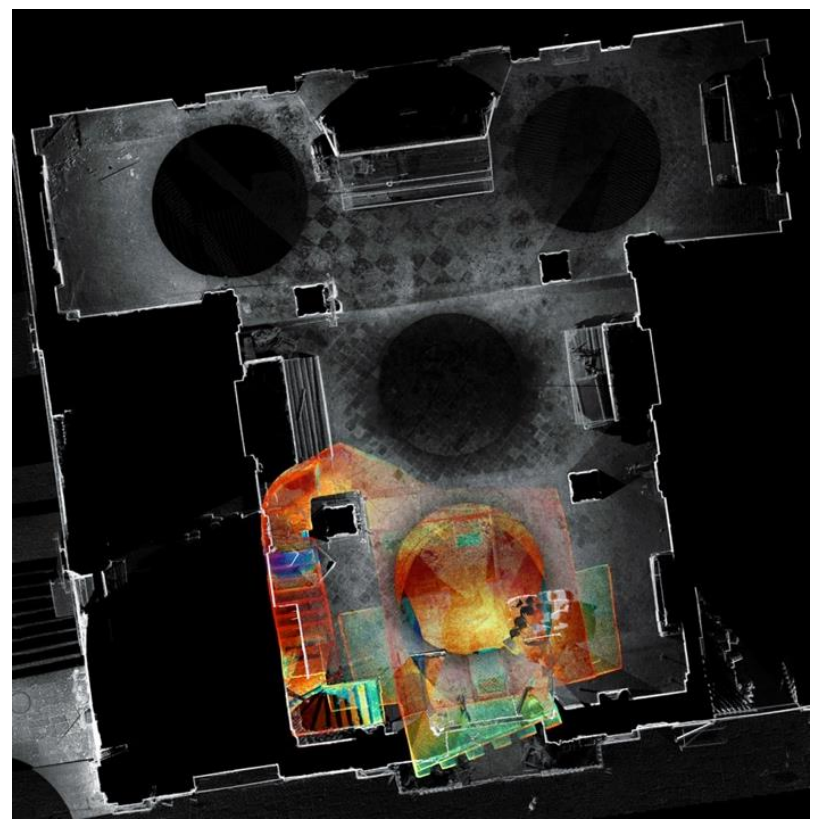

Figure 6 . The point cloud treated with different colors and densities to build a special three-dimensional model

Similarly to what was done for the Castel Capuano staircase, then, by modulating the density and color of the point cloud, a representation was done to visualize, through a play of transparency, the spacial relationship between the underground crypt, the interior of the upper church and the placement of the original pillars. (Figure 6)

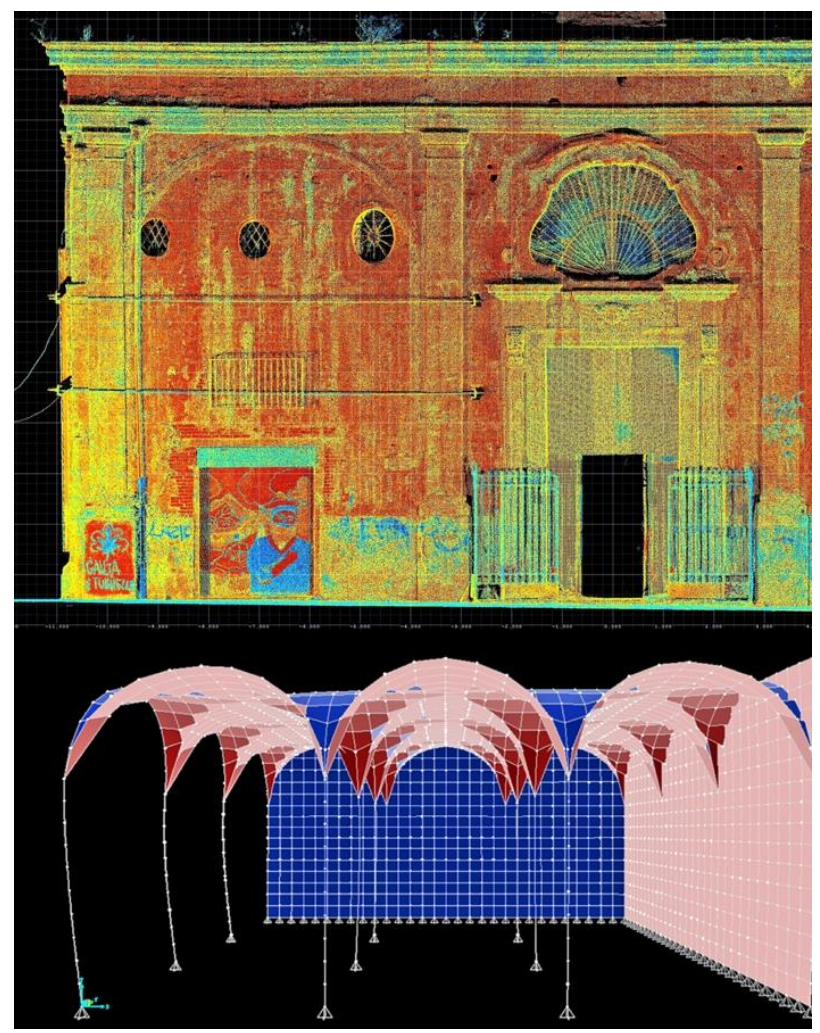

Figure 7. The point cloud of the façade and the structural behavior model.
Outside, the acquired cloud allowed for detailed analysis of the deformation state of the façades: it was possible to highlight and quantify a lateral facade rotation and estroflexion mechanism, which is associated with a flexion on the front facade cornice The analysis allowed engineers to choose between structural behavior models, built into structural analysis software, those who had returned the same deformations. (Figure 7)

In essence, the experience done confirms how the use of innovative technologies, such as the laser scanner, is today essential for a knowledge of the state of fact of the building for the architectural restoration project: knowledge that is not limited to the mere metric detection, but responds to the fundamental necessity of a wide multidisciplinary survey, providing a solid basis for this.

\section{QUERYING THE DATA ${ }^{\mathrm{b}}$}

The multidimensionality of the complex point cloud suggests the possibility of experimenting with new forms of analysis that can exploit not only metric information but also all the other scalar information contained therein.

This information, properly analyzed and questioned, can give rise to innovative representations that can display some special features of the detected surfaces.

This is particularly useful for the analysis of degradation and deformation states of architectural elements.

Through these particular representations, that use false color to color the points depending on the variation of some parameters, such as the reflectance value recorded by the instrument, the laser scanner becomes a real diagnostic tool that can visualize and quantify invisible aspects of the artefact.

\subsection{The Hall of the Busts in Castel Capuano complex}

In the specific case of the Hall of the Busts in Castel Capuano complex, survey forms and representation have been explored for the real geometrical interpretation of the artifacts searching for deformations or significant alterations, related to pathologies or specific events occurred during the construction.

In the Hall of the Busts, one of the biggest hall in the south of Italy entirely covered by frescoes, it has been realized an accurate reading of the painted surfaces reflectance's variations, looking for anomalies due to previous restorations, specific decay processes and washout caused by the previous crumbling roof covering.

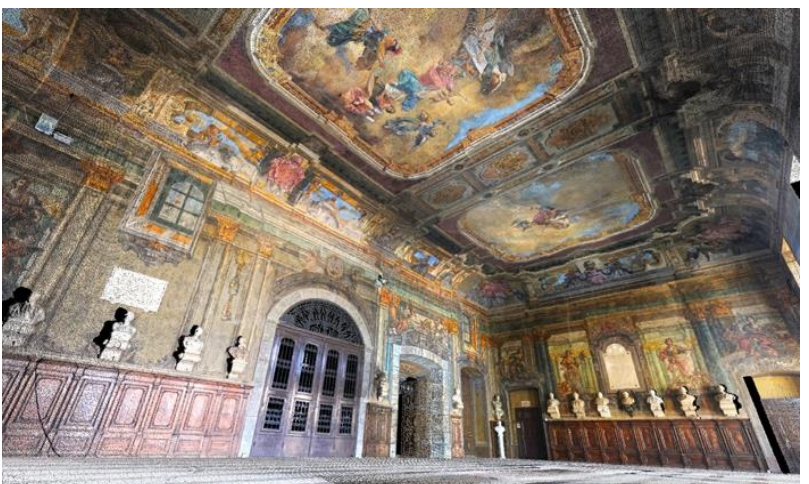

Figure 8. The complex point cloud of the Hall of Busts

To achieve this goal, the survey has been done with a laser scanner driven to a resolution of 1 sample per $\mathrm{cm}^{2}$ at 10 meters from the scanner. The acquired point cloud has been colored using a Nikon D700 camera with Nikkor $20 \mathrm{~mm}$ lens accurately put and regulate on the scanner for a minute acquisition of the 
chromatic datas of the frescoes. To maintain a widespread homogeneity and density of information on all surfaces without being forced to use automated post-processing filtration and, therefore, to retain the original data as much as possible, the total points cloud of the Salon required execution of 10 scan positions. This is to ensure a zenithal acquisition of the surfaces to be detected with particular attention to the homogeneity of the luminance data which varies according to the incidence angle of the laser light. The single point clouds have been registered with hybrid methods (target + Multi Station Adjustment algorithms) to reach standard deviations significantly lower than the maximum precision of the scanner. To achieve an homogeneous color of all the points with RGB data, each image was captured with 5 different degrees of exposure and then processed using High Dynamic Range (HDR) technique.

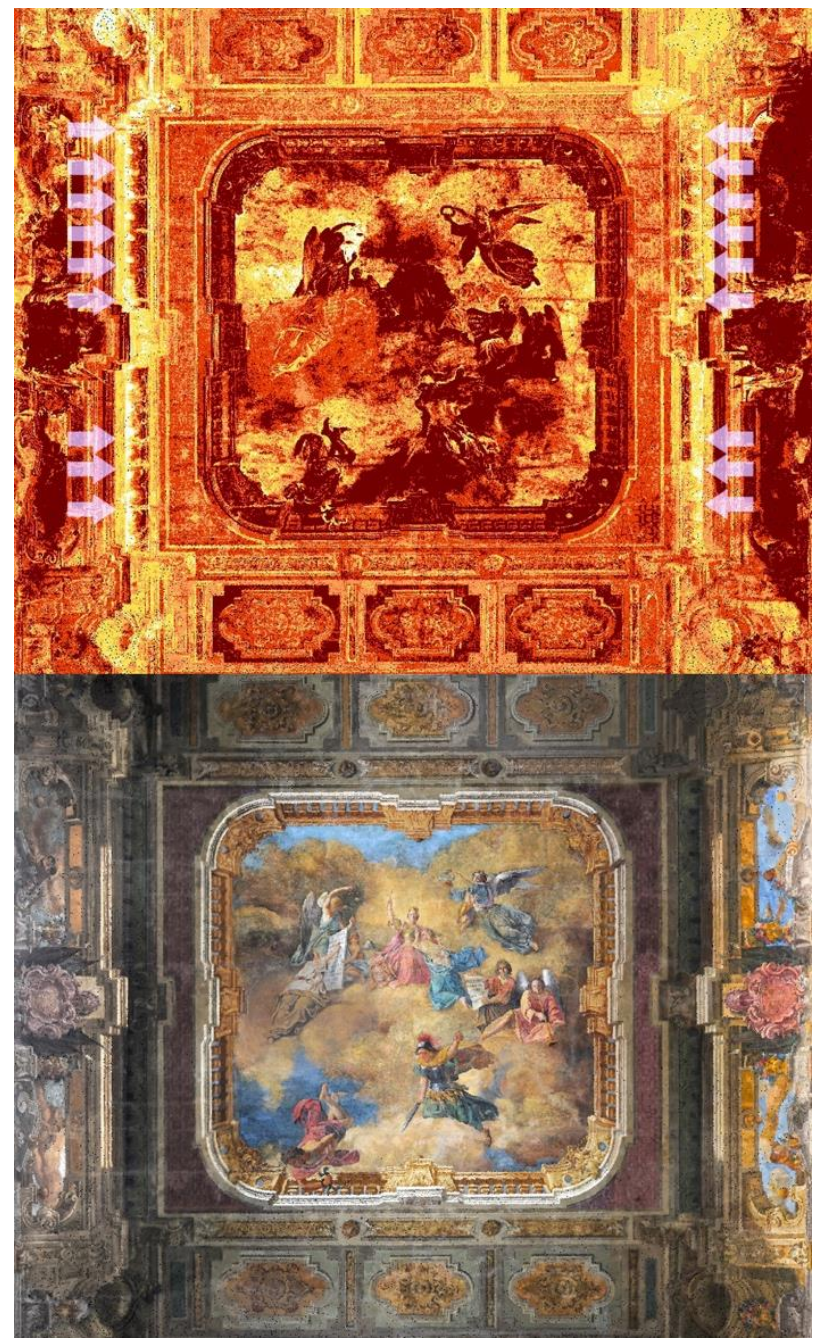

Figure 9. Comparison between colored point cloud with reflection data and RGB data.

Once the acquisition work has been completed, data has been queried with some software tools. The primary objective of the experiment was to carry out a diagnostic study on the state of degradation of the frescoed surfaces through the analysis of reflectance obtained from the instrument.

The Hall, in fact, has been subject to several restorations over the years, the most recent of which were carried out between 2000 and 2002 and between 2005 and 2006, designed and directed by officials of the competent Superintendence. These consisted of a reconstruction of the missing parts of the ceiling decoration and the restoration of the paintings of the north and east walls of the Salon, the paintings of Saloncino and the epigraphs and coats of arms decorating the Salon.

The space, in fact, suffered the detachment of large portions of ceiling decorations due to the 1980 earthquake and the moisture infiltration due to the damaged roof and the precarious conditions of the meteoric water disposal system

The effects of the degradation were manifested by efflorescence, which caused the decohesion and detachment of the mortar of the preparative layers, the progressive detachment and loss of the pictorial film and the chromatic alterations due to the effect of humidity on tempered paintings. Finally, alterations in the materials used in previous restoration work were obvious: cement or gypsum plastering, retouching, and chromatic altered protection.

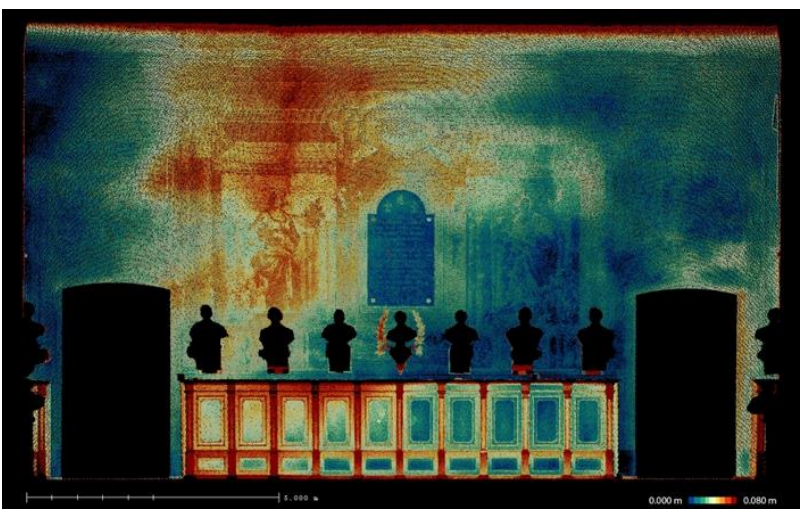

Figure 10.

In order to obtain an effective reading of such interventions and alterations, various chromatic scales have been elaborated for coloring, in the most effective way, the point cloud of the Hall in false color, depending on the reflectance data recorded by the instrument. Through the reflectance, in fact, irregular areas in the material surface composition were visible and corresponding to restoring parts of frescoes dating back to the restoration of 2005-2006, or to areas of intervention of previous restorations, consolidated or reintegrated with materials and films that have altered the surface material composition.

Some linear traces of surface chromatic alteration that traversed the fake pavilion vault were also very well identified.

These lines have been related to the wooden rib groove that supports the thin masonry shell, especially in the flat central part. The highlighting of these traces through the reflectance, in fact, suggests that they correspond to points of greater humidity transmission coming from the wooden ribs in direct contact with the extrados of the shell. (Figure 9)

Another field of investigation, faced with the direct analysis of point clouds, is that of the analysis of the real geometry of the frescoed surfaces of the Hall, in search of discontinuities and formal alterations invisible to the naked eye, precisely because of the presence of frescoes itself.

For example, in the southern wall of the Hall of the Busts, a slight discontinuity was found in the fresco plaster that vertically slides the wall to a third, approximately, from the left corner. To analyze and even quantify this alteration, the acquired point cloud is colored in false color, depending on the deviation of each point from a reference interpolator flat surface. In this way it was possible to point out a marked swelling that affects a fairly extensive area around the above mentioned discontinuity, whose maximum arrow from the reference area was approximately $8 \mathrm{~cm}$. (Figure 10) 


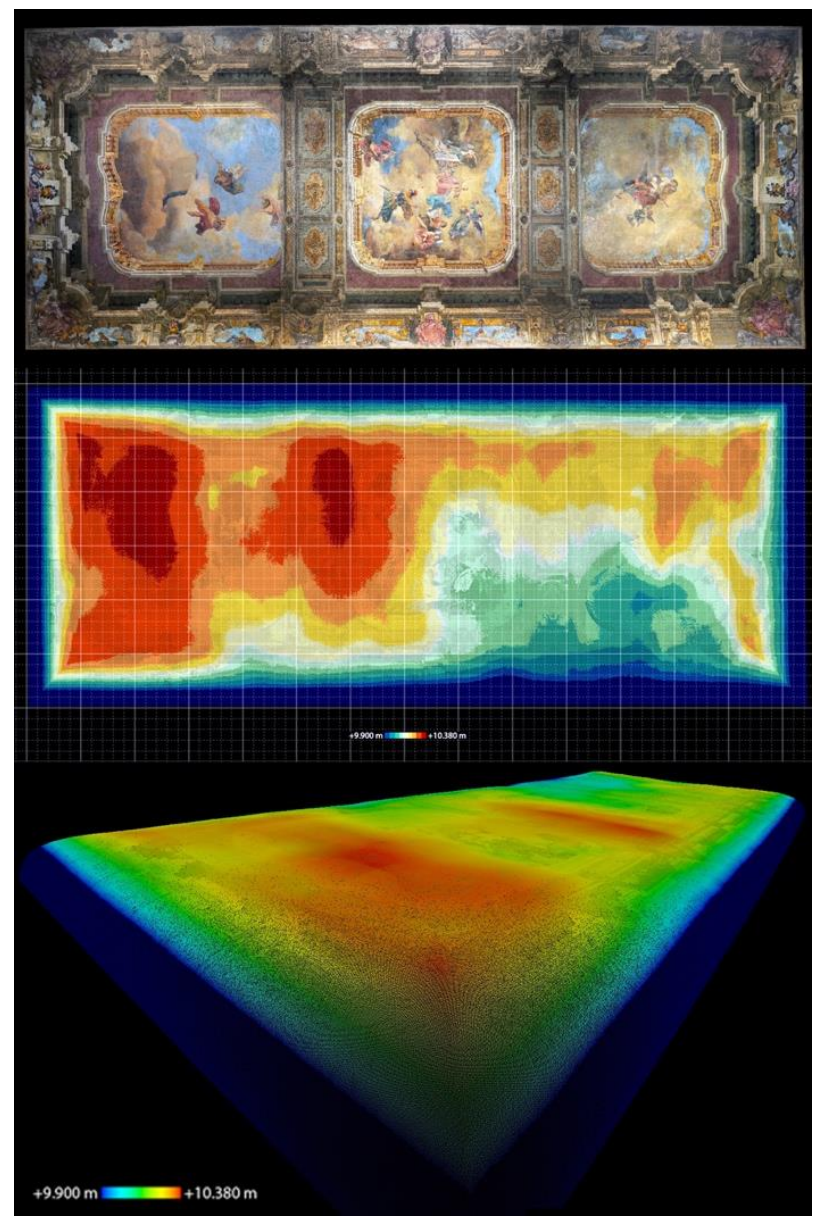

Figure 11.

Finally, in extracting the longitudinal section of the point cloud in the Hall, an unexpected noticeable irregularity in the horizontal level of the false masonry pavilion vault covering the large hall has been highlighted. This irregularity is also invisible to the naked eye, mainly due to visual disturbance consisting of the continuous presence of prospective / architectural decorations present in the intrados, which make it difficult to distinguish real shadows from painted shadows.Even in this case, the acquired point cloud was colored in a false color as a function of the deviation of each point from a horizontal reference level (not interpolator) placed at a height of 9.90 meters from the floor.

In this way, we could highlight significant swellings and subsidences that cover a differential of about $40 \mathrm{~cm}$ and attest to the maximum detected point of the surface at $+10,370$ and the minimum point (in the flat part of the pavilion) to approximately $+9,97 \mathrm{~m}$ from the floor. (Figure 11)

The integration of metric data with radiometric (reflectance) and chromatic data has allowed not only to highlight the relationship of such irregularities with the decorations themselves, but also the interaction between these and the invisible wooden structure supporting the false vault, pointing out the necessity of predicting, during the design of the restoration, further in-depth analysis on a few portions of masonry and decorated plaster of the Salon and the use of the same survey technologies also for the extrados of the room, to be carried out within the volume that surpasses the fake vault, in order to study such interactions without any margin of uncertainty.

\subsection{The facades of the monumental complex of Castel Nuovo in Naples}

In the survey of the facades of the monumental complex of Castel Nuovo in Naples, in addition to provide documentary evidence of the current status, some special analyses have been carried out with diagnostic purposes, the results of which have been crossed with specialized and multidisciplinary investigations for the purpose of reading the historical stratifications and the identification of the degradation of stone materials.

Since the earliest studies on the monument, it became clear how much the ancient material of Castelnuovo was stratified and how much the image, in the appearance unitary, was instead marked by the traces of the various historical events that characterized the multi-century history of the building.

With the partial covering of the moats, the viceroyal and eighteenth-century additions, as well as the subsequent twentieth-century liberation operations, the articulated transformations of the artefact on, the one hand, allowed the preservation of part of the original Aragonian masonry, and on the other hand, demanded the execution of substantial complementary and restorative interventions that affected both the original thick tuff masonry and the base and towers covered with variously piperno rock blocks of $15 / 20 \mathrm{~cm}$ thick. The present image of the ancient manor is the result, as is wellknown, of a liberation restoration begun at the beginning of the 20th century; works that, following the criterion of isolation, have brought the building back to the Aragonese time, sacrificing the subsequent stratifications. Over the centuries, there have been many transformations linked mainly to its intended use use, from a palace to fortress, up to the present with its predominantly museum purpose.

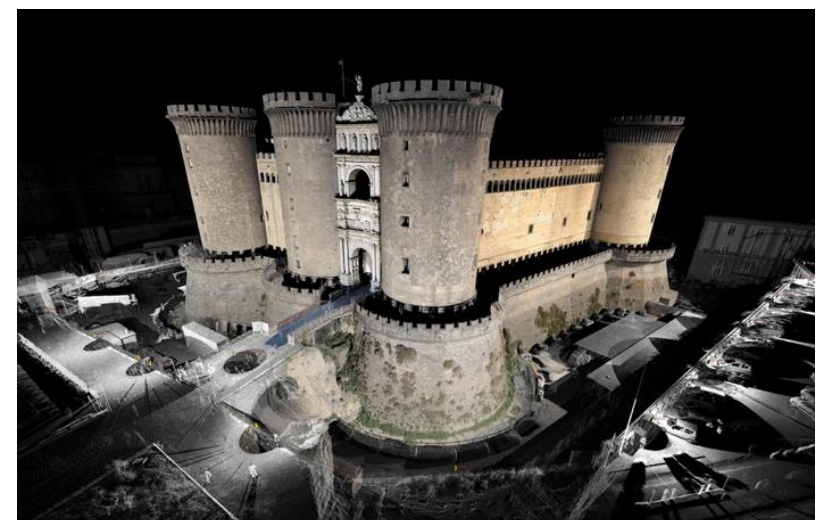

Figure 12. South-west view of the acquired dot cloud, indicating the scanning points.

In order to better support with evidence such stratifications, it has become necessary to carry out surveys with advanced techniques which led to the acquisition of important dimensional information that was the basis for the subsequent graphic return. Starting from the orthoprojection of the point cloud by the laser scanner, colored with RGB data of highresolution photographs taken by the camera connected to the device, it was possible to map a macro - areas for materials and construction techniques and the forms of degradation associated with them. The high definition of these measurable images and photographic documentation have been extremely important tools for identifying different construction techniques and recognizing degradation patterns.

Realizing images in different light conditions has also allowed us to document the main characters of the altered surface, while, to clearly appreciate the more minute elements, a series of 
close-up photographs were taken in tangential or lightening conditions. This approach has enabled, in this first phase of the study, to proceed, by analyzing the altered artefact in a timely manner, trying to study the effects caused by the degradation, disintegrating them into chromatic heterogeneity, discontinuities and surface irregularities. Considering the chromatic variation as a sign of a state of alteration (for example, to recognize the nature of a biological patina or a stain), it was possible to detect: dye or tonal variations due, for example, to the addition of a foreign substance to the support (stain); saturation variations, linked to the progressive loss of material for the sputtering of a dye or the erosion of a surface (erosion); brightness variation, determined by the presence of a superficial deposit. (Figure 13) At the same time, the integrate use of real ortoprojections, of the point cloud, colored in fake color (depending on the variation of luminance data) has been of great importance

Through the study of the variation of this parameter it is possible to detect anomalies and disomogeneities in the reflectance of the masonry wall with regard to the individual stone walls and for the observation of differences in the material and for the detection of patents and surface alterations. Finally, this study was supplemented with the results of laboratory analyzes performed by the petrograph expert group.

In particular, the survey has covered three of the exterior facades - south, west, and north - and all facades facing the interior courtyard of the architectural artifact.

To obtain a sufficiently dense and homogeneous point cloud with such a scanner to provide a reading of the actual geometry and state of degradation of the artifact, up to the scale of the single ashlar stone, the scanning positions were distributed with some regularity along the perimeter of the facades, spaced in such a way as to guarantee the covering of the geometry of all the protruding and receded parts, and to compensate, with the overlapping of contiguous scans, the inevitable density variations of the each point cloud which gradually degrade towards the farthest parts of the scanner. (Figure 12)

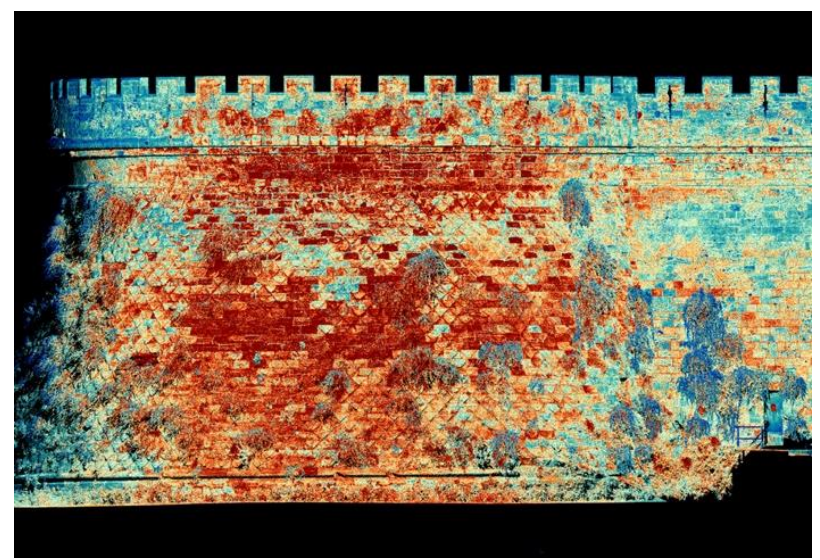

Figure 13. Orthoprojection of the tower tower stand points cloud, colored in false color depending on the variation of luminance.

A Nikon D700 camera with a $20 \mathrm{~mm}$ Nikkor lens, fixed and calibrated to the scanner, was used to capture the actual color of the surface, with which hundreds of photo captures were taken at the same time as scanning capture. Through the software, in fact, it was possible to color each scanned spot from the scanner with the RGB data from the photographic sensor, in order to obtain, after elaboration, a reading of the chromatic variations of the individual ashlar stone directly on the obtained point cloud.

Also in the case of Castel Nuovo, two particular questions from the acquired data were elaborated: one related to the reflectance values of the stone surfaces and the other one related to the metric information for the analysis of the real geometry.

With regard to the first point, it is appropriate to specify that, to obtain a homogeneous analysis of th reflectance, the luminance value has a particular importance in the point cloud, because it is an indicative scale of the variation of the electromagnetic energy that returns to the instrument with respect to the energy from this is emitted with the laser pulse. This value depends directly on the reflectance, the surface properties of reflecting light, and inversely by other parameters such as the angle of incidence of the laser pulse relative to the surface, the degree of moisture present in the material or the distance from the point to detect from the instrument. Taking these parameters into account, the study of the luminance, the reflectance of a surface and its abnormalities, can provide important information about the characteristics and state of surface preservation of the artifacts.

For this purpose, for each facade of the castle, different orthoprojections of the point clouds were elaborated in false color, depending on the variation of luminance values recorded by the instrument. These have been used to identify and highlight areas with widespread surface alterations or punctual abnormalities related to the material differences or the conservation status of each ashlar stones.

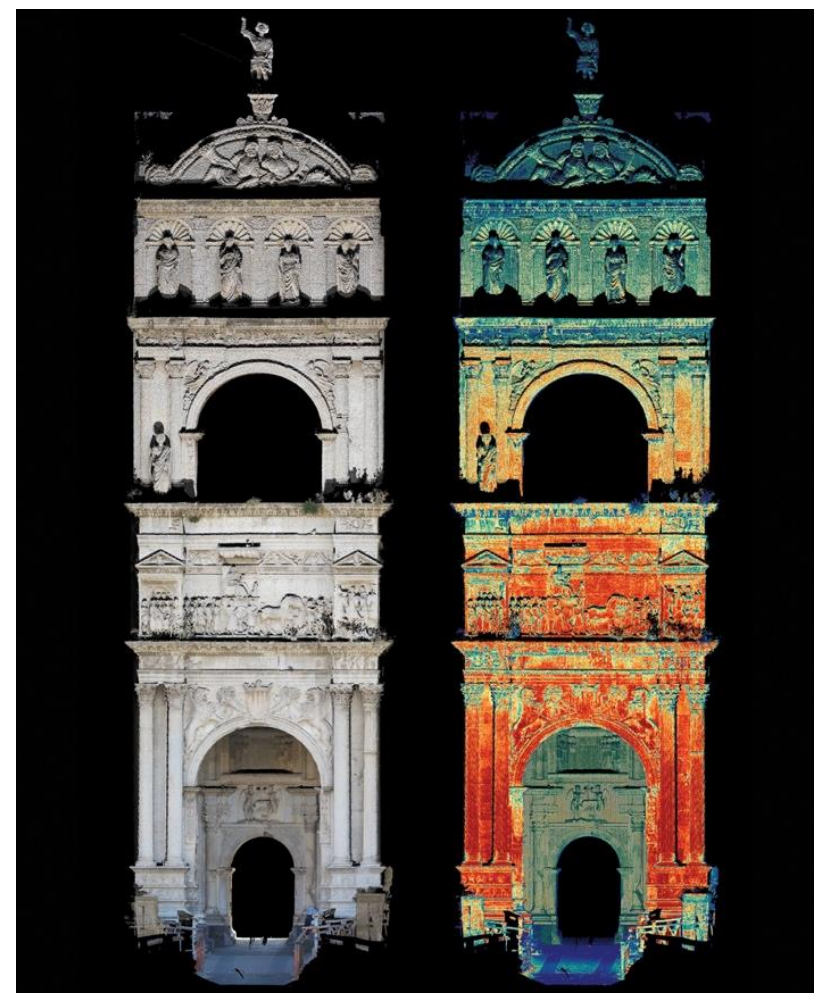

Figure 14. Orthoprojection of the Aragonese arc dot cloud with actual RGB data and false color depending on the luminance variation.

Thanks to this method, it was possible to highlight how the articulated transformations of the product, which have involved considerable material integration, have resulted in the formation of a heterogeneous degradative state characterized in particular by a diffused phenomenon of erosion and chromatic alteration caused by environmental pollution and disruptive action from soluble salts produced by marine aerosols.

The state of conservation described above, spread equally across all prospects, is well-highlighted on the southern front. The basement area of the south curtain, which is mainly covered with piperine, integrated during the restoration process, shows 
erosion phenomena affecting the entire upper area up to the merlot wall delimiting the ancient paths. The shoe inclination allows to demarcate a long band that is affected by intense draining phenomena with local patina, determinating a clear chromatic alteration. There are also efflorescences located in particular on the Stand crowning merlature of the base, due to chlorides and nitrates, caused by water infiltrations from the walkway at the first level of the Castle.

The heterogeneous coloration affecting the cladding stone of the base is determined by organic (musk and lichen) and inorganic (oxidation) patents and by localized stone integrations in new blocks of pipeline and in ignimbrite (from Campania).

With regard to the faces facing the inner courtyard of Castelnuovo, particular forms of degradation are present on the East Front. This prospect today presents a tuff coating characterized by a heterogeneity of degradative phenomena caused by the different surface texture consistency. It is to be noted, in fact, that large parts of the curtain have been repaired which did not affect the entire thickness of the masonry. In fact, the presence of tombstones of the stratified type of the thickness of about $15 / 20 \mathrm{~cm}$ used to regularize the façade during the restorations carried out in the 1930s, overlapping the original masonry, which - as can be seen from historical photographic documentation - showed a precarious state of conservation. During the transformations and restoration works or pseudolike, but still recent, in order to cope with localized erosion of the surface of the tuff, some of them were also coated with a pink mortar.

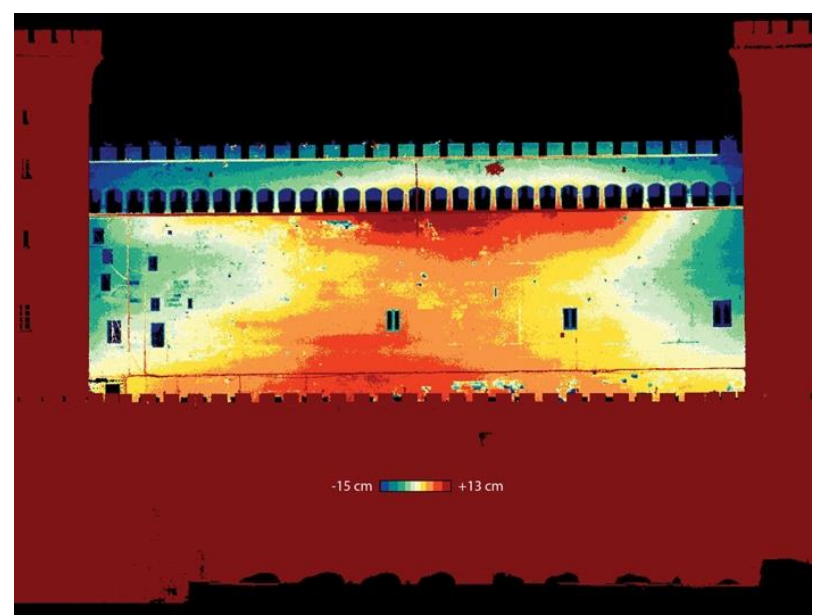

Figure 15. False color chart of the geometric deformation of the flat wall between the Guard and the Golden towers.

These interventions have therefore resulted in the use of new differently worked tuff slabs and the laying of a plaster coating which, at different times, have developed forms of diversified degradation, in particular erosion and stains caused by rain water washout, such as to characterize the stone surface from a heterogeneous color. Serious erosion phenomena also determine the precarious state of preservation of the stone elements of the aedicule near the Baron entrance Hall.

Regarding the interrogation of metric information, however, it has been possible to investigate the real geometry of surfaces in search of discontinuities, formal alterations and deformations that are often difficult to evaluate with the naked eye and are almost always impossible to quantify with accuracy.

This type of query is made by reconstructing the ideal geometry of a real element to compare, through software, the deviation of the real geometry detected by the ideal reconstructed, by visualizing and quantifying, point by point, deformation states and geometric alterations often, but not always, are symptomatic of a lesioning condition. (Figure 15)

With this technique, for example, it has been studied the flat wall between the Guard and Gold towers, reconstructing the ideal interpolator surface of the wall and coloring, in false color, the point cloud according to the deviations of each point from that flat surface.

The result, which must necessarily be compared with historical information, the lesioning framework and the structural model for its correct interpretation, visually returns the wall deformation geometry with respect to its ideal plan and locates and quantifies precisely the points of maximum and minimum deviation.

\subsection{The south facade of the Caserta Palace}

Even in the case of the south facade of the Caserta Palace, it was possible to obtain, questioning the point cloud, an analysis of the surfaces detected by reading the reflectance values made possible by coloring in false color (according to a suitable color scale ) of each point of the point clouds, depending on the change in the return energy percentage, read by the scanner sensor, compared to that of the output.

Given the logical impossibility of performing frontal and zenith scans throughout the high part of the facade when reading reflectance values, account should be taken of this variation. Therefore, it is necessary to partially divide the color charts and to perform different readings depending on the different scanning points and their position relative to the facade.

Reflectance's analyzes were then compared with the data emerging from thermography. On this occasion, the investigation was carried out using an AVIO TVS 500 thermographic machine. The operations concerned the part of the prospectus starting from the planking level of the square and up to the portion of the first stringcourse.

The different thermograms were then straightened and mosaicized to obtain two thermografic maps: one for the basement and one for the upper one that starts from the first stringcourse.

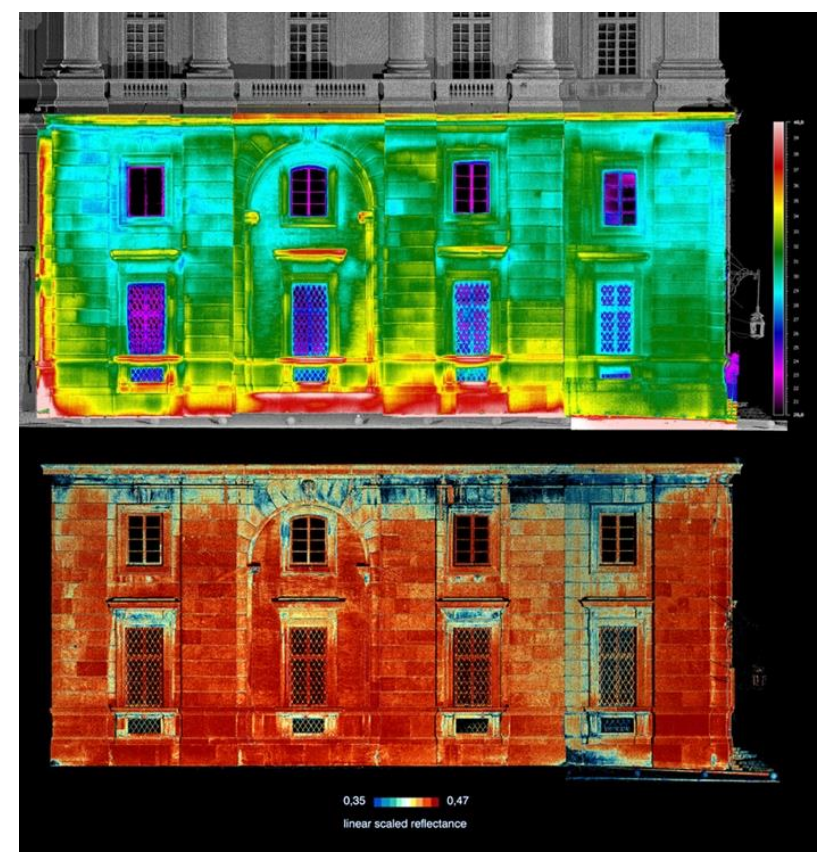

Figure 16. Comparison between colored point cloud with thermographic data and reflection data. 
These thermographic maps, in which the color bands correspond to the isotermic lines, are designed to analyze a number of related issues, in particular, the pathologies of degradation and the difference in the materials. For this purpose, further thermographic images were elaborated, four for the low part of the facade, four for the upper one, which were then compared with the laser scanner data. (Figure 16)

\section{CONCLUSIONS ${ }^{\mathrm{c}}$}

From the experiences and experiments that have been made in the last ten years of activity, it is clear how the laser scanner survey has a double utility for the knowledge of the architectural artifacts: on the one hand, it can immediately get metric precision surveys, innovative graphic returns and threedimensional models directly derived from the elaborate point cloud.

On the other hand, the complex point cloud can be considered a non-interpretative and multidimensional "document" of a temporally defined state of fact, that can be queryed with software tools to investigate visible and invisible aspects of the artifact, even at a distance of time.

Both of these features are partially in common with other similar technologies, such as "photo-scanning", which is having a great development in recent years.

However, from the point of view of restoration, there are many peculiarities that make the laser scanner a completely different tool, in a substantial way, compared to the measurement systems based on automatic photogrammetric processes.

In the complex point cloud of laser scanner, each single point represents a direct measurement of which we know and we can also control the approximation. In photo-scanning the generation of the points is charged to the photogrammetric process, entirely managed by the software and depends of the quality of the photographic survey, without real control by the operator over the software process and the accuracy of point measurement.

Furthermore, the possibility to associate sensors, other than the photographic one, to the scanning system and the fundamental acquisition of reflectance data, makes the laser scanner an irreplaceable knowledge tool for the interests of the Conservation of the Historical Heritage.

This tool, together with a truly multidisciplinary cognitive approach, is an integrating element that can correlate the history of architectural artifacts with that of damages and state of conservation, providing an integrated reading that put together, in a contextual manner, the historical archive research with the knowledge of the material stratifications of architectural elements.

\section{REFERENCES}

Aa.Vv., 2008. Diagnostica e conservazione. L'insula 14 del Rione Terra, a cura di A. Aveta, Napoli.

Aa.Vv., 2008. Il cantiere della conoscenza, metodologie e strumenti per la conservazione e il restauro, a cura di R.A. Genovese, Napoli.

Aa.Vv., 2009. Restauro e tecnologie in architettura, a cura di D. Fiorani, Firenze.

Aa.Vv., 2011. Dalla conoscenza al progetto, Metodologie e strumenti per la conservazione e il restauro, a cura di R.A. Genovese, Napoli.
Amore R., Aveta C., Buccaro A., 2016. La chiesa dei Santi Cosma e Damiano in Napoli: ricerche e studi per il restauro, FREQUENZE_conservazione/restauro n. 2, Napoli.

Aveta, A., 2013. Il 'Gabinetto' della Regina Giovanna: il recupero della scala. In Aa.Vv., Castel Capuano. La cittadella della Cultura giuridica e della Legalità. Restauro e valorizzazione, Napoli, pp. 185-190.

Aveta A., Marino B.G., Vitelli G.P., 2011. Realtà, verità ed interpretazione dell'architettura storica: frontiere e prospettive dei contemporanei strumenti di rilevamento, in Aa.Vv., Il Disegno delle trasformazioni, Atti delle giornate di studio, Napoli, 1 e 2 dicembre 2011.

Aveta, A., 2009. Architettura storica e conservazione, in Aa.Vv., La diagnostica per il restauro del patrimonio monumentale, Napoli, pp. 29-40.

Bartolucci, D., 2009. Principi di laser scanning 3D, Palermo.

Fancelli, P., 1997. L'entità veritativa dello stato di fatto monumentale, in «'ANANKH» n.19, pp. 22-28.

Marino, B.G., 2006. Restauro e autenticità. Nodi e questioni critiche, Napoli.

Marino, B.G., 2009. Una diagnostica per i valori materiali ed immateriali: la conservazione della Chiesa rupestre di S. Maria di Piedigrotta a Pizzo Calabro. In Aa.Vv., La diagnostica per il restauro del patrimonio culturale, Napoli, pp. 285-294.

Nava M.L., 2012. Museo provinciale campano di Capua. Guida alle Collezioni, Foggia.

Vitelli, G.P., 2013. Il restauro del Salone dei Busti di Castel Capuano e l'uso della tecnologia laser scanner 3D, in Aa.Vv., Conoscere, Conservare, Valorizzare, a cura di R.A. Genovese., Napoli, pp. 371-381.

Vitelli, G.P., 2013. I rilievi con il laser scanner. In Aa.Vv., Castel Capuano. La cittadella della Cultura giuridica e della Legalità. Restauro e valorizzazione, Napoli, pp. 107-111.

Vitelli, G.P., 2013. Roberto Di Stefano e la fotogrammetria architettonica, in Aa.Vv., Roberto Di Stefano. Filosofia della Conservazione e Prassi del Restauro, a cura di A. Aveta e M. Di Stefano, Napoli, pp. 326-331.

Vitelli, G.P., 2013. Il rilievo laser-scanner come registrazione delle modificazioni, in Aa.Vv., Pompei Accessibile. Per una fruizione ampliata del sito archeologico, a cura di R. Picone, Roma, pp. 349-358.

Vitelli, G.P., 2014. L'uso delle nuvole di punti complesse per indagini sulle superfici affrescate del Salone dei Busti di Castel Capuano a Napoli, in Aa.Vv., Colore e colorimetria contributi multidisciplinari vol. XA. Atti della X Conferenza del Colore. Genova, pp. 175-184. 